\title{
A Gestalt-terapia na universidade: da f(ô)rma à boa forma
}

\section{Gestalt-therapy at the University: from the mold to the good shape}

\author{
Luciana Loyola Madeira Soares * \\ Professora e supervisora de estágio em Psicologia Clínica do curso de graduação em \\ Psicologia do Centro Universitário Celso Lisboa - CEUCEL, Rio de Janeiro, RJ, Brasil
}

\section{Resumo}

Este texto apresenta uma discussão sobre as características do trabalho de supervisão em Gestalt-terapia nos Serviços de Psicologia Aplicada dos cursos de graduação em Psicologia. Com uma presença que ainda pode ser considerada recente na universidade, a Gestalt-terapia propõe uma abordagem no estágio em Psicologia Clínica que não se confunde com uma formação de gestaltterapeutas. Sua estratégia passa pelo desdobramento de possibilidades criativas da relação do supervisor com o estagiário e, deste, com os clientes em atendimento. A condução do trabalho na supervisão visa à melhor forma possível para configurar a singularidade do aprendizado das habilidades do futuro psicólogo clínico, e, para isso, distancia-se da rigidez das formatações teóricas e de um enquadramento fechado em dispositivos técnicos.
\end{abstract}

Palavras-chave: Gestalt-terapia, Supervisão, Formação acadêmica do psicólogo.

\begin{abstract}
This text discusses the supervision in Gestalt-therapy at the Services of Clinical Psychology in the graduation in Psychology. Recently installed at the universities, Gestalt-therapy doesn't intend to prepare new gestalt-therapists, but aim to develop creative relationship possibilities between the supervisor and the trainee, and between this one and his clients. The process in supervision is driven towards finding the best form as possible in order to figure the singularity of learning the abilities of becoming a clinical psychologist. According to Gestalt-therapy purposes, that means to stay as far as possible from strict rules of theory and of close technical resources.

Keywords: Gestalt-therapy, Supervision, Academically upbringing of the psychologist.
\end{abstract}

O jogo de palavras tem por objetivo brincar com o sentido e os muitos sentidos que a presença da Gestalt-terapia na academia trouxe para a 
graduação em Psicologia. Tomamos como ponto de partida para esta reflexão duas perguntas:

- Como introduzir o sentido de contra-cultura que primordialmente caracteriza a Gestalt-terapia no contexto predominantemente científico e racional da academia, no que diz respeito especificamente ao estágio em Psicologia Clínica?

- O que efetivamente a Gestalt-terapia tem oferecido como contribuição à formação do psicólogo?

Embora já tenhamos lecionado a Gestalt-terapia como disciplina teórica na graduação em Psicologia, vamos aqui nos ater às especificidades de nossa experiência na supervisão em Gestalt-terapia nos Serviços de Psicologia Aplicada das universidades.

Acompanhando os alunos ao longo das disciplinas teóricas da graduação em Psicologia, observamos a ansiedade crescente em verem aproximarse o início do estágio no SPA. Os sentimentos e as fantasias são as mais contraditórias: desejo, medo, ousadia, sucesso, fracasso, impasses, abandono pelo cliente, agressões, rejeições, silêncio, etc. Tudo isso vai sendo expresso mais ou menos claramente, como que se pedissem um aval ao mestre, esperando um sinal de reconhecimento de prontidão para os futuros atendimentos. Pontes (2004, p.154) aponta semelhante observação obtida em sua experiência como docente e supervisora da graduação em Psicologia:

É interessante observar que nossos estudantes são expostos a estes dois aspectos fundamentais do conhecimento, de uma maneira, pode-se dizer, sequencial e nem sempre útil: primeiro, sentam-se nas salas de aula e tomam conhecimento das teorias existentes: depois vão para o campo da prática. A dificuldade da articulação teoria-prática se faz, então, visível.

Notamos que os estudantes seguem buscando desenvolver o suporte possível para a atividade clínica não só através do estudo, mas principalmente constatamos que vão aproximando-se do conhecimento teórico das diferentes linhas teóricas, percebendo suas afinidades para efetuar futuras escolhas, em boa parte inspirados na relação de identificação e de admiração com seus mestres. Lembremo-nos que o oposto também se dá, pois a rejeição a uma abordagem teórica pode estar diretamente relacionada com algum entrave relacional com um determinado modelo de atitude de um mestre.

Dias (1998, p.22) é outra autora que se inquieta com os procedimentos que rondam o estágio supervisionado, apontando a ênfase colocada na função do supervisor:

Contudo, o que se apresenta de imediato no ideário da formação é o Estágio Supervisionado constituindo-se um lugar de chegada, marcado pelo término do ciclo básico e do cumprimento de um determinado 
conjunto de disciplinas instrumentais. Esse lugar de chegada, funciona de certo modo como um sinal indicador de que um conjunto de noções do saber psicológico já está de posse do aluno, aguardando apenas o momento de estágio para dele se valer. A premissa que orienta tal movimento se ampara num repertório de certezas onde se reforça a idéia de que os "objetos conceituais" da psicologia correspondem necessariamente aos ideados a serem encontrados, quando uma dada realidade foi investigada. Não obstante isso, ao mesmo tempo se inicia a fase profissionalizante do currículo, com as respectivas disciplinas que Ihe dão sentido, configurando o lugar de partida no projeto de integralização "formação/conclusão" e de inserção no "mercado" de trabalho. Esse lugar de partida, entre outras imagens, reflete a assunção de uma iniciação e a aquisição de um certo credenciamento para a vida profissional. Esse segundo movimento é perfeitamente entendido, já que o supervisor, geralmente se apresenta como alguém que dispõe de domínio e experiência comprovada em determinada área de atuação.

Dias (1998, p.22) é outra autora que se inquieta com os procedimentos que rondam o estágio supervisionado dentro das universidades. Sua crítica dirige-se ao fato do estágio funcionar como uma síntese da grade teórica e técnica das disciplinas curriculares e lugar de sua respectiva aplicação, constituindo-se meramente num tempo de preparação do futuro profissional para um mercado de trabalho que, em tese, espera por esse psicólogo que supostamente sabe sobre as demandas que vai encontrar e o que deve fazer. Assim, Dias aponta ceticamente para a ênfase colocada na função do supervisor como aquele que, por dominar a experiência de sua área de atuação profissional, está devidamente dotado de instrumental e de certezas a serem transmitidas e, portanto, credenciado para ser o agenciador do processo de inserção do aluno no mercado de trabalho.

Mais adiante (p.23), a autora acrescenta que o estagiário apresenta:

\begin{abstract}
... o pedido incessante de um script, já que é o Estágio Supervisionado, o lugar designado para aprender na "prática" aquilo que tecnicamente só se domina em "teoria". Através de uma visão superior e de um roteiro de ações mais ou menos previstas, o estagiário acredita estar a salvo do erro e garantido em suas futuras investidas.
\end{abstract}

Baptista (2000) precisamente intitulou seu questionamento à formação do psicólogo como 'A Fábrica de Interiores', expressão que indica uma perspectiva de engrenagem na graduação que produz profissionais em série como numa linha de montagem, pondo ênfase no treinamento de atributos tecnicistas para o futuro exercício da profissão. De acordo com este autor, isso implica em excluir a subjetividade do estagiário de seu 
próprio processo de estágio, já que são levados a especializar-se em respostas já dadas por outros. Segundo o autor (p.28), o que podemos esperar surgir de uma educação assim fundamentada é um “... futuro promissor ordeiro, mas castrado".

Chegamos então a um primeiro ponto relevante na escolha do aluno em tornar-se estagiário de um supervisor que se oriente pela Gestaltterapia: o primado da inspiração não manipuladora ou sedutora que o mestre é capaz de mobilizar em seus alunos nas disciplinas teóricas, mesmo que estas não versem diretamente sobre Gestalt-terapia. Se houver sedução, esta emerge da interação do aluno com o encantamento do mestre por sua escolha de abordagem teórica. Por outro lado, entendemos que o mestre tenha condições de instigar seus alunos a desenvolver um encantamento para seu próprio processo de conhecer, voltado para sua maneira singular de identificar-se com uma determinada abordagem teórico-clínica. A isso, preferimos chamar de inspiração. Se o aluno encanta-se com o encantamento com que seu mestre expressa sua maneira de relacionar-se com a abordagem escolhida, o mestre encanta-se com o encantar-se do aluno em seu modo singular de conhecer e de descobrir-se em suas identificações. Há nisso um profundo respeito, aquele que surge do encontro entre alteridades.

Entendemos que essa é a expressão do que seja a formação do psicólogo enquanto um processo de transformação: tirá-lo da f(ô)rma que despotencializa e deixá-lo descobrir-se, revelar-se e potencializar-se ao partir em busca da melhor forma possível para si, criando-se e recriando-se a cada momento na experiência compartilhada de transformar-se. Se estamos investindo na formação de um futuro profissional agente de transformação, precisamos repensar o quanto a graduação em Psicologia tem sido reprodutora de repetidores em série, formatadora de profissionais da repetição, legitimadores da lógica do sistema capitalista, dirigidos para a eficiência que o mercado de trabalhos espera deles.

Num contexto acadêmico que i(e)nforma o estudante com um diversificado arsenal de teorias e técnicas, que juntas, não fazem muito sentido, cabe àqueles supervisores que representam a Gestalt-terapia nos Serviços de Psicologia Aplicada nas universidades um papel de tirar da $f(\hat{o})$ rma de instigar à boa forma, de acordo com a lei da pregnância ou boa forma da Psicologia da Gestalt, como encontramos em Burow e Scherpp (1985, p.26) “...percebemos um padrão de maneira a emprestar-lhe a melhor gestalt possível.". Por melhor gestalt possível naquele contexto de experiências que é o grupo de supervisão indicamos que seja o processo de assimilação conduzido por cada um, produzindo configurações que traduzem sua relação com o mundo a partir de elaborações pessoais de suas histórias de vida. Entendemos 
com isso que nossa tarefa está para além de instrumentalizar o estagiário para a prática profissional através da articulação entre teoria e técnica - a supervisão pode adquirir a função de conectar o graduando com o mundo, promovendo o desdobramento da percepção que tem de sua experiência proporcionando-Ihe a ampliação de recursos pessoais. $\mathrm{Na}$ perspectiva gestáltica, assim, estamos criando a possibilidade de desenvolvimento profissional para um psicoterapeuta.

Mas, reportando-nos à segunda pergunta lançada no começo desse texto, como a Gestalt-terapia, através de seus representantes na academia, pode vir a contribuir para isso?

No cotidiano das supervisões no SPA consideramos alguns aspectos como sendo particularmente relevantes para a legitimação da Gestaltterapia enquanto um saber e fazer que se impõe pela característica de contra-cultura. Por este termo não pretendemos dar a entender que estamos dispostos a desconstruir outros saberes e fazeres já constituídos na tradição acadêmica e marcados por cientificidade nos procedimentos. De fato, a academia é, por excelência, o lugar onde lidamos com a onda de racionalismo e tecnicismo que assola as práticas psicológicas. Nós, Gestalt-terapeutas, somos com frequência interpelados por colegas e estudantes com indagações (mais ou menos sutis) sobre a suposta falta de consistência teórica de nossa abordagem, cuja marca ainda está associada a um vistoso conjunto de técnicas capazes de mobilizar grupos em "happenings" terapêuticos de feição sedutora e validade duvidosa. Devido ao grande crescimento da Gestaltterapia no Brasil, esta já é conhecida como psicoterapia de maior duração, mas talvez ainda de menor profundidade, por estar equivocadamente ligada ao mal compreendido conceito de "aqui-eagora". Fica evidente, portanto, que temos a tarefa de estabelecer uma interlocução com os representantes das demais abordagens psicoterápicas na academia com base na consistência filosófica, teórica e prática da Gestalt-terapia de modo a estabelecer uma justa visibilidade à abordagem no território da universidade. E o SPA configura-se como o local onde exerceremos nossa tarefa.

Vamos então lançar um olhar ao estágio - tempo que marca a inevitável passagem do aluno a condição de estagiário, ressaltando seu comprometimento com o futuro desempenho da atividade profissional. Momento de o estudante alinhavar o "lá-e-então" das disciplinas da graduação, da história de vida, dos projetos pessoais e dos profissionais, com o "aqui-e-agora" do que sabe, do que não sabe, do que sabe que quer, do que sabe que pode e do que sabe que não pode... É quando aquele que esteve passivo e destituído de subjetividade ao longo de vários semestres emerge a partir da experiência com seus conflitos. As gestalten em aberto vêm à tona devido às provocações que o predomínio das incertezas sobre as certezas promove no sujeito. É 
tempo de dar vez ao desconhecido que se pensa conhecido, que se pensa ameaçador, que se pensa ilusão e desilusão, que se sonha, que se deseja, que se evita, e que se fantasia. Momento de descrença e de aposta; de renovar os investimentos, de reinventar a própria experiência de existir.

O estágio funciona inclusive como um momento que implica um dispositivo de análise diagnóstica da instituição e de suas relações. Este pode ser efetivamente um momento de subverter-se uma ordem em que predomina a massificação do aprendizado de uma tarefa que não pode ser massificada: a de formar (e não, deformar) o psicólogo como agente de transformação. Até então no curso de graduação em Psicologia, não se supunha que o estudante devesse ou precisasse escutar, escutar-se, olhar, olhar-se, disponibilizar-se ao outro que com ele dividia a sala de aula. No academicismo isso não conta. Na situação grupal de supervisão o que promove subversão é a abertura ao outro. Ali está a possibilidade de encontro com o outro a partir da experiência compartilhada de aprender, de duvidar, de falar para alguém que vai escutar, de escutar alguém que vai falar. É um encontro com o outro em sua plena alteridade, portanto não pressupõe a igualdade ou a unanimidade de experiências, pois, uma vez que está na contramão da padronização, põe em evidência a singularidade do processo de desenvolvimento de cada estagiário no grupo em que se insere.

O aprendizado no estágio, numa perspectiva fenomenológicoexistencial, embute a proposta humanizar-se ao aprender a cuidar de humanos. Recorremos a Novaes de Sá (2003, p.167):

\begin{abstract}
Uma clínica com base hermenêutica, portanto, pretende-se um espaço de tematização de sentido, de desnaturalização dos sentidos já previamente dados, na ampliação dos limites dos horizontes de compreensão. Pensar o sentido da clínica é desconstruir a idéia de aplicação de uma técnica já dada, de uma psicotecnologia neutra que visa ajudar pessoas a atingirem objetivos pessoais. O espaço clínico busca acolher e sustentar a vida enquanto questionamento. Em outras palavras, a clínica não fala pela vida, permite que ela fale por si mesma através dos fenômenos que aparecem e que não tem o caráter de verdade ou mentira, mas de possibilidades de sentido em jogo na abertura que constitui o espaço de diálogo clínico.
\end{abstract}

Num estágio fundamentado na perspectiva gestáltica lidamos com o domínio de condutas operacionais recheadas de promessas de verdades absolutas e, sim, com a permanente construção compartilhada de articulações entre a subjetividade e os conteúdos pedagógicos apresentados nas disciplinas curriculares. O desdobramento do raciocínio clínico tendo como referencial a Gestalt-terapia sustenta-se no entrelaçamento entre os pilares teórico-filosóficos da abordagem com a 
disponibilidade do estagiário para aceitar sua condição de não-pronto, assim como em perceber a Psicologia como prática não-pronta, o que se evidencia na experiência do grupo. Recorremos a Perls (1977, p.31) para ilustrar a indissociabilidade entre sujeito e o campo no qual está inserido: "Ninguém é auto-suficiente; o indivíduo só pode existir num campo circundante". Mais adiante, na mesma página, ele afirma que:

O estudo do modo como o ser humano funciona no seu meio é o estudo do que ocorre na fronteira de contato entre o indivíduo e seu meio. É nesse limite de contato que ocorrem os eventos psicológicos. Nossos pensamentos, ações, comportamentos e nossas emoções são nossa maneira de vivenciar e encontrar esses fatos limítrofes.

Isso requer do supervisor a habilidade de favorecer no grupo o encantamento com a permanente possibilidade de criar-se e recriar-se a partir da experiência na supervisão e com os clientes que cada um está atendendo. Podemos chamar isso de desapego à rigidez do modelo e permitir-se fluir de acordo com o olhar com olhos de quem quer conhecer. De acordo com Dias (1998, p.28) "Assim seria: supervisão, um encontro onde se desdobram efeitos para todos os seus agentes, entendendo esses efeitos como rearranjos operados nessa ordem do invisível e que perpassam os diferentes processos de subjetivação".

0 conceito de fronteira-de-contato apresenta-se como eixo para o trabalho em Gestalt-terapia e, portanto, constitui-se como eixo para o supervisor que pratica esta abordagem na clínica-escola também. Permitindo que o grupo observe o impacto com o relato dos conteúdos dos atendimentos, o supervisor encaminha uma pesquisa fenomenológica, formulando indagações, que levam a novas indagações, sem a intenção de chegar a uma resposta, mas buscando desdobrar possibilidades de uma determinada perspectiva. Cada um vai apropriarse dessa experiência de modo peculiar, assimilando apenas o que lhe é possível e que esteja conectando-se com sua história de vida, assim, há como ativar a fronteira-de-contato, a conexão entre alteridades, cuja expressão se evidencia no modo como o vir-a-ser se presentifica para dar conta do imponderável. PHG (1997, p.43) esclarecem a importância deste conceito para a Gestalt-terapia, entendido enquanto interação, movimento em direção à relação:

Quando dizemos 'fronteira' pensamos em uma 'fronteira entre', mas a fronteira-de-contato, onde a experiência tem lugar, não separa o organismo e seu ambiente; em vez disso limita o organismo, o contém e protege, ao mesmo tempo que contata o ambiente.

Segundo Fonseca (2005, p.32), o conceito de fronteira-de-contato pode ser apreendido muito mais na perspectiva temporal do que na físicoespacial, por abrigar a transformação e todos os afetos implicados no processo de vir-a-ser; é um conceito que se obtém com o vivido “... A Fronteira de Contato não se dá como relação sujeito-objeto. A Fronteira 
de Contato é a tensão vivencial da projetação da possibilidade: projetação do pré ser compreensivo da possibilidade". A fronteira é o próprio limiar da mudança, trazendo em seu bojo possibilidades e limites, os quais, ao delimitar trocas, territórios conhecidos e desconhecidos, apontam condições que precisam ser reconhecidas e devidamente respeitadas. Perls, Hefferline e Goodman (1997, p.45) indicam-nos o que para eles seja o resultado da experiência do sujeito no campo "Crescimento é a função da fronteira-de-contato no campo organismo/ambiente". Cada grupo, portanto, funcionará de maneira auto-regulatória, e constituirá uma experiência única e irrepetível de crescimento.

A experiência da mudança é posta em evidência ao longo de todo o processo vivido no estágio. Importa o que impacta, o que provoca a fronteira-de-contato de modo a instigar à transformação que resulta no crescimento citado por Perls, Hefferline e Goodman (1997) que, no caso do estágio, estamos falando de um crescimento de cada um em sua singularidade existencial, assim como das relações no grupo como um todo. No entanto, como não funcionamos na universidade como um curso de formação de Gestalt-terapeutas, não podemos nem devemos cobrar do estagiário um desempenho da ordem de sua conversão em gestalt-terapeuta. Precisamos desenvolver critérios específicos de avaliação do aproveitamento do período de estágio - condição obrigatória em todos os cursos de graduação em Psicologia. Inquietantes indagações acompanham-nos durante esse percurso: como podemos decidir quem está apto a ser psicólogo, assumindo futuramente a tarefa de psicoterapeuta? Que habilidades devem ser desenvolvidas nos anos da graduação? Como o estágio em Psicologia Clínica favorece o surgimento do psicoterapeuta? Partindo destas indagações, novas indagações abrem-se em permanente discussão na academia, o que nos permite constatar que não há respostas definitivas, nem tanto consenso em torno do tema. Porém, acreditando que todo mestre traz consigo seus mestres, guardamos na memória uma terna lembrança daquela que, de alguma maneira, tem o lugar de mestra de todos nós Gestalt-terapeutas brasileiros: Therese Tellegen. No primeiro Encontro Nacional de Gestalt-terapeutas, realizado em 1987 no Rio de Janeiro, uma das mesas de discussão trazia como tema justamente como decidir quem pode ser Gestalt-terapeuta. O debate já estava demorado e não se apresentava um caminho para consenso, quando do meio da platéia, delicadamente Therese levantou-se e, com a voz suave pediu licença para participar e sugerir que, em sua opinião, estava apto a ser Gestalt-terapeuta quem apresentasse disponibilidade para a mudança. Deste momento em diante 0 que se seguiu foi 0 encerramento do debate. De fato, este tem sido o critério de avaliação mais importante para o exercício de nossa condição de supervisores na 
clínica-escola: estar permanentemente apostando no vir-a-ser do estagiário e, atentos a sua aposta em seu vir-a-ser.

A supervisão na universidade por ser realizada necessariamente em pequenos grupos de estagiários propicia uma situação que é fundamental para a promoção da experiência de contato: o estar com o outro, o aprender compartilhado, da escuta ao relato do outro e relatar ao outro. Ao relatar seu atendimento, o estagiário relata-se, sendo a supervisão criada singularmente para cada relato apresentado. Observamos o quanto o estagiário presentifica-se em seu relato. Entendemos que caiba ao supervisor conectar o graduando com o mundo através de intervenções que abram o caminho para sua própria experiência de contato, pois acreditamos que por esta via, ele possa redirecionar o investimento em si mesmo, percebendo a importância de buscar sua própria psicoterapia. Indicamos que faz parte da tarefa do supervisor instigar o estagiário a conhecer seus recursos pessoais, vindo a descobrir e fortalecer seu suporte para as articulações que terá que fazer, abrindo-se sensivelmente ao que é capaz de potencializá-lo e a para o que pode despotencializá-lo em sua presença no mundo. Novaes de Sá (2003, p.166) nos esclarece: "A mesma teoria se torna fundo de diferentes formas em cada psicólogo". Fica claro que cada sujeito se relacionará de maneira singular com a abordagem teórica proposta no estágio, assim como esta proporcionará diferentes impactos em cada um dos presentes no grupo de supervisão. A diversidade de experiências e percepções da supervisão em grupo contribui para uma inserção mais ampla do futuro psicólogo em sua ação no mundo a partir do que consegue ampliar de percepção de si no contexto dos atendimentos e das supervisões. Consideramos, portanto, toda a bagagem que cada estagiário manifesta, assim como nos fala Novaes de Sá (2003, p.166):

[...] a conduta e a identidade profissional do terapeuta jamais se reduzem a uma questão de escolha teórica ou do aprendizado de técnicas, mas implica sua singularidade existencial como um todo, incluídos aí todos os seus saberes não conceituais e até mesmo os não representacionais.

Deste modo, ratificamos que tornar-se psicólogo não se resume a exibir habilidades teórico-técnicas, ferramentas que, se tomadas separadamente, conduzem o psicólogo ao isolamento nos gabinetes, desconectando-o de sua função de agente de transformações no mundo. Bastos (2003, p.12 e 13) vem em nosso auxílio, ilustrando:

[...] quando tal subjetividade irrompe, não só questiona a ordem vigente, como também traz à tona um grande potencial de forças de mudanças, oferecendo-nos oportunidades para gestarmos novas ordens, outras formas de relação. 
Contudo, é sabido que no ambiente universitário é necessário apresentar graus, aprovar ou reprovar, que são, portanto, exigências de avaliação a serem cumpridas, tanto para os supervisores quanto para os estagiários. Funcionando na abordagem gestáltica, como fazer a interlocução com as normas que selam a formação dos graduandos, sem vedar os canais de desdobramento do fluxo criativo?

Nos grupos de supervisão temos adotado a prática de uma construção compartilhada de desenvolvimento na aquisição de conhecimentos e experiência na atuação do psicólogo clínico. Paralelamente às questões e temas que emergem dos relatos dos atendimentos realizados pelos estagiários, selecionamos textos para leitura e discussão no grupo, de maneira a fundamentar a prática que vai se montando a partir de olhares que são lançados aos fenômenos relacionais tanto os que se referem ao grupo de supervisão, quanto à relação com o cliente. Como instrumento de avaliação adotamos a solicitação da produção de um texto individual que denominamos 'Registro de Aprendizagem'. Este é tecido tendo como foco a experiência de cada um na malha relacional do grupo, estabelecendo uma reflexão sobre os atendimentos e, fundamentando-os com os textos selecionados. Pretendemos obter uma formulação da singularidade do processo de transformação vivenciado pelo estagiário em seu percurso no estágio clínico. Bem de acordo com o pensamento expresso por Tellegen no I Encontro de Gestalt-terapeutas, a disponibilidade para a mudança é o principal critério de avaliação. Como esta ocorre durante todos os momentos de trabalho nas supervisões, em forma de proposta reflexiva, a percepção da transformação pessoal e grupal fica legitimada pelo próprio estagiário e pelo grupo. Uma nota, traduzindo uma aprovação ou uma reprovação, não deve incidir como uma espada sobre a cabeça do estagiário ao final do semestre, pois ele se vê envolvido em seu processo de investimento ao longo de todo o período, assim como o grupo se envolve com o processo de comprometimento de cada um dos participantes. Deste modo, acreditamos que o grupo de supervisão em Psicologia Clínica na abordagem gestáltica, somente através de um processo de aprendizagem que inclui a auto-regulação, desenvolva as mínimas habilidades para o trabalho clínico: estar com o outro, disponibilidade, aceitação das diferenças e, conhecer o que potencializa e o que despotencializa cada um. Podemos afirmar que isto implica enfim, em experienciar a fronteira-de-contato, correndo todos os riscos do vir-aser. Incluímos aqui abrir e fechar gestalten, poder conviver com gestalten incompletas, buscando melhor configuração possível para um processo sempre inacabado (o da formação do psicólogo fora da universidade).

Sendo assim, o que efetivamente o estágio em Psicologia Clínica na abordagem Gestáltica pretende promover? 
De acordo com o que expusemos a tomada de consciência da fronteirade-contato permitirá ao graduando a condição de problematizar sua prática seja qual for a orientação teórico-clínica a ser futuramente adotada.

Encaminhamo-nos para trazer algumas considerações finais para este texto sem a intenção de fechar conclusões, como convém quando adotamos a Gestalt-terapia como referencial - abrindo, fechando e abrindo gestalten. Apontamos que a presença da Gestalt-terapia no SPA da universidade não pode ser resumida a uma mera oposição ao esquema vigente na formação de psicólogos, sob o risco de tornar-se uma outra linguagem de controle dentro do sistema acadêmico. Tendo sido bem-vinda no SPA de diferentes universidades em nosso país, a Gestalt-terapia apresenta-se implicada no processo de transformação da formação do futuro psicólogo enquanto voltada para a sensibilidade nas relações na produção de subjetividade. Assim, tornarmo-nos presentes na academia na busca de interlocução com outros saberes, sem a pretensão de esgotar com nosso viés a compreensão dos fenômenos humanos. A Gestalt-terapia é contra-cultura no que diz respeito a defender a legitimidade dos movimentos humanos e trabalhar pelo que mobiliza o sujeito em direção a relacionar-se com o meio em condição de genuína mutualidade. Propõe, portanto, desobedecer ao instituído somente na medida em que este seja considerado inassimilável. Para tanto, é fundamental 'olhar com olhos de quem quer conhecer', para tudo e considerar o que deve ser assimilado através de um processo digestivo, o qual começa, como toda digestão saudável, por uma boa mastigação. Não sendo assim, será pura introjeção, o que, no caso de nosso foco de estudo neste texto, implica numa adesão artificial à abordagem, a partir de um processo de estágio que exclui o próprio estagiário.

Destacamos que o supervisor fundamentado na Gestalt-terapia tem por função a trans-missão, a missão de servir de acompanhante nessa passagem, que é feita através de sentidos, afetos, apostas, de criar o que não está aí, de instigar a ir além do que está encapsulado, formatado inclusive do que é esperado de sua função como supervisor. Este, saindo da $f(\hat{o}) r m a$ do que deve ser um padrão de supervisão instrumentalizadora na universidade, legitima o poder de criação, reinventando o que pode ser uma supervisão na clínica-escola, e segue junto com seus estagiários em meio à diversidade, em busca da boa forma, a melhor forma possível para cada momento, para cada grupo, para cada estagiário. 


\section{Referências Bibliográficas}

BAPTISTA, L. A. A Fábrica de Interiores - a formação psi em questão. Niterói: Eduff, 2000.

BASTOS, R. L. Psicologia, Microrrupturas e Subjetividades. Rio de Janeiro: E-papers, 2004.

BUROW, O. A.; SCHERPP. K. Gestaltpedagogia. São Paulo: Summus, 1985.

DIAS, R. M. S. Dos Encontros em Supervisão - devenires na formação do psicólogo. In: Temas em Psicologia- Sociedade Brasileira de Psicologia. Ribeirão Preto: SBP/USP, 1998, v.6, p.21-29.

FONSECA, A. H. L. Ensaios em Gestalt-terapia. Maceió: Pedang, 2005.

NOVAES DE SÁ, R. Considerações Heideggerianas sobre a Psicoterapia e a Técnica. In: BASTOS, R. L. Psicologia, Microrrupturas e Subjetividades. Rio de Janeiro: E-papers, 2004.

PERLS, F. A abordagem Gestáltica e a Testemunha Ocular da Terapia. Rio de Janeiro: Zahar Editores, 1997.

PERLS, F; HEFFERLINE, R. e GOODMAN, P. Gestalt-terapia. São Paulo: Summus, 1997.

PONTES, R. Super-visão em grupo: uma visão interpessoal. In: VILHENA, J. A Clínica na Universidade. São Paulo: Edições Loyola, 2003.

\section{Endereço para correspondência}

Luciana Loyola Madeira Soares

Centro Universitário Celso Lisboa, Rua 24 de maio, 797, CEP 20950-091, Sampaio, Rio de Janeiro-RJ, Brasil

Endereço eletrônico: lucianasoares@infolink.com.br

Recebido em: 31/03/2008

Aceito para publicação em: 21/01/2009

Editor responsável: Laura Cristina de Toledo Quadros

\section{Notas}

*Psicóloga, Gestalt-terapeuta, Especialista em Psicologia Clínica e Educacional pela PUC/RJ . Mestre em Psicanálise, Saúde e Sociedade da Universidade Veiga de Almeida UVA, RJ, Brasil. 